talenta

\title{
THE ASSOCIATION BETWEEN EXPRESSION OF EPIDERMAL GROWTH FACTOR RECEPTOR WITH PRIMARY TUMOR VOLUME OF NASOPHARYNGEAL CARCINOMA PATIENTS
}

\author{
Indah Asmara Gustarini ${ }^{1}$, Audi Wahyu Utomo ${ }^{1 *}$, Budi Sutikno ${ }^{1}$, Achmad Chusnu Romdhoni ${ }^{1}$ \\ ${ }^{I}$ Otorhinolaryngology Head and Neck Surgery Departement, Faculty of Medicine, Universitas Airlangga Surabaya, Indonesia
}

\section{Abstract}

Introduction: Nasopharyngeal carcinoma (NPC) is a malignancy derived from nasopharyngeal epithelial cells One of the molecular NPC markers is cluster of Epidermal Growth Factor Receptor (EGFR) who have responsible against the proliferation, differentiation, apoptosis, metastasis and drug resistance.

Objective: Tumor development was triggered by the excess population of the Epidermal Growth Factor Receptor (EGFR). EGFR expression associated with tumors size, positively nodules and advanced tumor stage in NPC patients.

Methods: Using Cross-sectional as study design. Formalin-fixed paraffin-embedded biopsy specimens were obtained. The expression of EGFR was studied with immunohistochemistry using EGFR polyclonal antibody (Bioss, USA). Assessment of the staining was performed by pathologist consultant used histoscore. The Pearson's correlation test was used to determine the correlation between expression of EGFR and primary tumor volume of nasopharyngeal carcinoma. Statistical significance was defined as $\mathrm{p}<0.05$.

Result: Total samples are 19 patients. The result of EGFR expression in NPC patients with a primary tumor volume of $1-50 \mathrm{ml}$ is 5 samples with a weak positive expression and 4 samples with moderate positive expression. NPC with a primary tumor volume of 51-100 $\mathrm{ml}$ is 2 samples of negative expression, 1 sample of weak positive expression, 3 samples with moderate positive expression and 2 samples with strong positive expression. NPC with primary tumor volume $>100 \mathrm{ml}$ is 1 sample weak positive expression and 1 sample strong positive expression. Statistical analysis using Pearson's exact test was obtained $\mathrm{p}=0.047$ with a correlation coefficient 0.461 . EGFR expression from all of the patients there was 2 samples (10.53\%) negatives, 7 samples $(36.84 \%)$ weak positive, moderate positive was 7 samples $(36.84 \%)$, and strong positive 3 samples $(15.79 \%)$. Conclusion: There was an association between the expression of EGFR with the primary tumor volume of nasopharyngeal carcinoma.
\end{abstract}

\section{Article Info}

Keywords:

Nasopharyngeal carcinoma, expression of EGFR, primary tumor volume.

\section{*Corresponding author:}

Address: Jl. Mayjen Prof. Dr. Moestopo No. 6-8, Gubeng, Kota Surabaya

e-mail: audiwahyutomo@gmail.com

\section{INTRODUCTION}

Nasopharyngeal carcinoma (NPC) is a malignancy derived from lymphoepithelial and epithelial tissues of nasopharynx. Nasopharyngeal carcinoma is the most common head and neck malignancy with locoregional metastasis [1-3]. The assessment of therapy response is using staging, but in fact patients with the same stage of NPC could have different responses [4]. this proved that staging is not accurate to predict the therapy response for NPC. Epidermal Growth Factor Receptor (EGFR) is supposedly associated with NPC primary tumor volume, and acts as a marker to predict the therapy response and for giving targeted therapy.

Chua, et al. (2008) proved that the expression and EGFR level increased significantly in late stage of NPCs compared to those in early stages. The statement also supported by the study conducted in RSUP Dr. M. Djamil Padang that revealed EGFR expression increased in stage III and IV of NPC [5]. The EGFR examination and measurement of primary tumor volume expected to be the better predictors of therapy response of NPC. Until now the correlation between EGFR expression and primary tumor volume of NPC patients at Out Patient Department (OPD) of Otolaryngology Department, Dr. Soetomo General Hospital Surabaya has not been clearly known.

Primary tumor volume of NPC with high level EGFR expression known to have the better therapy response using targeted therapy [5], but not every NPC with high level EGFR gives complete response, but the other studies found that EGFR inhibition didn't bring significant result in restrict NPC proliferation. This might explained there is another pathway involved in NPC progresivity [5].
EGFR is a tyrosin kinase receptor that usually expressed in tumor epithelial. This receptor increased using biomolecular and immunohistochemistry examinations [6]. The increasing of EGFR expression also related with the increasing of NPC staging such as tumor volume, lymph node involvement, and distant metastasis that affect the prognosis [5]. Many studies found that the increasing of EGFR expression related with poor prognosis of NPC [7-10]. High EGFR expression in NPC had been reported in $80 \%$ NPC biopsies in Europe and around $85 \%$ NPC patients in China. EGFR expression detected in the late stage of NPC. In another study, 234 samples with squamous cell carcinomas about $31 \%$ EGFR positive and increased EGFR expression found in NPC patients [7-10]. Chua et al., found $89 \%$ positive EGFR expression using immunohistochemistry examination from NPC biopsies, meanwhile $11 \%$ with negative EGFR expression. Chua et al., concluded that there was no difference between EGFR expression and NPC staging, tumor size, lymph node enlargement, distant metastasis, age and gender [7].

The role of EGFR in the development of the NPC in many ways, such as improving the cell differentiation, inhibit local immune response, stimulate proliferation, induction angiogenesis, and inhibit apoptosis [5]. EGFR increase in some carcinomas, it's a transmembrane glycoprotein produced by e-erb-B2 proto oncogene and affected by EBV. Active EGFR will trigger three main signaling pathways Ras-Map kinase, Janus Kinase (JaK)/Signal Transducer and Activator of Transcription (STAT), Phospatidyl Inositol 3-Kinase (PI3K) that relate with EGFR activation, increasing of proliferation, cell motility and inhibit apoptosis. It also relate with carcinogenesis process that cause independent invasive growth epithelial layer of nasopharynx [11-14]. 
Recent studies try to explain the activation mechanisms and EGFR function, for the purpose of find a malignancy therapy. But in many studies stated that EGFR inhibition did not bring significant result in inhibit NPC proliferation. this shows that there is another pathway that engages in NPC progresivity $[5,6]$.

Many contradictive results from previous studies led us to do a research to find the correlation between EGFR expression and primary tumor volume Nasopharyngeal Carcinoma at OPD of Otolaryngology Department, Dr. Soetomo General Hospital Surabaya.

\section{MATERIAL AND METHODS}

This is a cross sectional study conducted in May 2017 until May 2018 for patients whom diagnosed with NPC and did first time check up at OPD of Otolaryngology Department, Dr. Soetomo General Hospital Surabaya.

The inclusion criterias are paraffin block of malignancy biopsies enough for EGFR immunohistochemistry examination and also NPC patients with nasopharyngeal focused head and neck CT scan at Dr. Soetomo General Hospital Surabaya. The exclusion criterias are NPC patients with broken paraffin block biopsies or did not fulfill the requirements during the process immunohistochemistry examination or patients that have already recieved definitive therapy such as radiotherapy, chemotherapy or combination, and also were not willing to follow the research.

EGFR expression examined with paraffin block thickness 3-5 $\mu \mathrm{m}$, when there was foung necrotic are then the paraffin block couln't be use. Endogenous peroxidation activity inhibit with $3 \%$ hydrogen peroxidation in methanol for 10 minutes with room temperature. This slice incubated in $10 \%$ lamb plasma in phosphatebuffered saline (PBS) for 30 minutes, then continued incubation in $4{ }^{\circ} \mathrm{C}$ using rabbit polyclonal antibody anti EGFR bs-0165R for 1 night. After that every slice given biotinylated antirabbit immunoglobulin for 10 minutes then incubated with streptavidin peroxidase complex for 45 minutes. Peroxidation activity visualized using 3.3-diaminobenzidine and also stain using hematoxylline.

EGFR expression is the precipitate intensity that smeared start from tawny until dark brown color at membran cell, cytoplasm, or both thru immunohistochemistry stained. EGFR expression evaluated into 3 semi visual quantitative scales. The outward evaluation/EGFR distribution evaluation using outward apprearanced by means of stained cells in 500-1000 cells or in 5-10 visual fields with 400x enlargement. The intensity evaluation of EGFR done with ascertained with the changes brownish red color. Immunohistochemistry stained using rabbit polyclonal antibody anti EGFR bs-0165R (Bioss, USA). The results based on distribution were: $0=$ no positive cell found, $1=$ positive cell $\leq 10 \%, 2=$ positive cell $11-50 \%, 3=$ positive cell 51 $80 \%, 4=$ positive cell $\geq 80 \%$. The results based on instensity were: $0=$ no color, $1=$ weak intensity color (light brown/ pale), $2=$ intermediate intensity color (brown), $3=$ strong intensity (dark brown). Histochemistry score is the multiplication between distribution and intensity with ratio scale. Final scores were: $0=$ negative, $1-2=$ weak positive $(+), 3-6=$ intermediate positive $(++)$, $7-12=$ strong positive $(+++)$. Evaluation scale: ordinal category, score 0-12. Evaluation done by anatomical pathology specialists.

NPC Primary tumor volume is the size of primary tumor that measured using head and neck CT scan focus on nasopharynx. Primary tumor volume measured using 3D volume measurement merk Philips Extended Brilliance Workspace. The contrast enhanced areas were colored and then combined to get the tumor volume. Tumor volume expressed in milli liter [15]. Scales with ratio measurement were done by radiology doctors.

Statistical analysis using descriptive analysis to calculate the distribution of EGFR expressions and primary tumor volume based on CT-scan findings using data ratio and Pearson's test with level of convidence $(\alpha)=0,05$. This study already got permission and approval by ethical committee Medical faculty of Universitas Airlangga-RSUD. Dr. Soetomo Surabaya.

\section{RESULT}

The result of the study is provided as below:

Table 1. NPC Patients Distribution

\begin{tabular}{|c|c|c|}
\hline Data & Number & $\%$ \\
\hline \multicolumn{3}{|l|}{ Age } \\
\hline $31-40$ & 4 & 21.05 \\
\hline $41-50$ & 10 & 52.64 \\
\hline $51-60$ & 3 & 15.79 \\
\hline $61-70$ & 1 & 5.26 \\
\hline $71-80$ & 1 & 5.26 \\
\hline \multicolumn{3}{|l|}{ Gender } \\
\hline Male & 15 & 78.95 \\
\hline Female & 4 & 21.05 \\
\hline \multicolumn{3}{|l|}{ Ethnic } \\
\hline Javanese & 15 & 78.95 \\
\hline Maduranese & 4 & 21.05 \\
\hline \multicolumn{3}{|l|}{ Occupation } \\
\hline Entrepreneur & 8 & 42.11 \\
\hline Housewife & 1 & 5.26 \\
\hline Farmer & 9 & 47.37 \\
\hline Domestic Employee & 1 & 5.26 \\
\hline \multicolumn{3}{|l|}{ Stage } \\
\hline I & 0 & 0 \\
\hline II & 1 & 5.26 \\
\hline III & 3 & 15.79 \\
\hline IV & 15 & 78.95 \\
\hline \multicolumn{3}{|l|}{ Primary Tumor Volume } \\
\hline $1-50 \mathrm{ml}$ & 9 & 47.37 \\
\hline $51-100 \mathrm{ml}$ & 8 & 42.11 \\
\hline$>100 \mathrm{ml}$ & 2 & 10.52 \\
\hline \multicolumn{3}{|l|}{ Histopatology } \\
\hline WHO I & 1 & 5.26 \\
\hline WHO II & 3 & 15.79 \\
\hline WHO III & 15 & 78.95 \\
\hline Total & 19 & 100.00 \\
\hline
\end{tabular}

The most age distribution of NPC patients is age range 41-50 years old 10 petients $(52.64 \%)$ patients, followed by age range $31-40$ years old 4 patients $(21.05 \%)$, age range $51-60$ years old 3 patients $(15.79 \%)$, age range $61-70$ years old 1 patient $(5.26 \%)$, and age range $71-80$ years old 1 patient $(5.26 \%)$. The youngest was 32 years old and the eldest was 73 years old. The most gender of NPC patients is male 15 patients $(78.95 \%)$, meanwhile female 4 patients $(21.05 \%)$. The comparison between male and female was 3.75:1. The most ethnic distribution of NPC patients is javanese 15 patients $(78.95 \%)$ followed by Maduranese 4 patients $(21.05 \%)$. The most occupational distribution of NPC is farmers 9 patients (47.37\%) followed by enterpreneur 8 patients $(42.11 \%)$, housewife 1 patient $(5.26 \%)$ and domestic employee 1 patient $(5.26 \%)$. The most staging distribution is stage IV 15 patients $(78.95 \%)$, followed by stage III 3 patients $(15.79 \%)$, stage II 1 patient $(5.26 \%)$, stage I no patient. The most primary tumor volume NPC is $1-50 \mathrm{ml} 9$ patients $(47.37 \%)$, followed by $51-100 \mathrm{ml} 8$ petients $(42.11 \%),>100 \mathrm{ml} 2$ patients $(10.52 \%)$. The most histological type is WHO type III 15 patients (78.95\%), followed by WHO type II 3 petients $(15.79 \%)$, and WHO type I 1 patient $(5.26 \%)$.

The correlation between EGFR expression and primary tumor volume NPC EGFR expression compares with primary tumor volume NPC:

Table 2. EGFR expression examinations with Primary tumor volume NPC

\begin{tabular}{|c|c|c|c|c|}
\hline \multirow{2}{*}{$\begin{array}{l}\text { EGFR Expression } \\
\text { (Histoscore) }\end{array}$} & \multicolumn{3}{|c|}{$\begin{array}{c}\text { Promary tumor } \\
\text { volume NPC }(\mathrm{ml})\end{array}$} & \multirow[t]{2}{*}{ Number } \\
\hline & $1-50$ & $51-100$ & $>100$ & \\
\hline Negative (-) & 0 & 2 & 0 & 2 \\
\hline Weak Positive $(+)$ & 5 & 1 & 1 & 7 \\
\hline Intermediate Positive $(++)$ & 4 & 3 & 0 & 7 \\
\hline Strong Positive $(+++)$ & 0 & 2 & 1 & 3 \\
\hline Total & 9 & 8 & 2 & 19 \\
\hline
\end{tabular}

Table 2 above shows the results of EGFR expression examinations on NPC with primary tumor volume $1-50 \mathrm{ml}$ were weak positive in 5 patients and intermediate positive in 4 patients. NPC with primary tumor volume 51-100 ml were negative in 2 patients, weak positive in 1 patient, intermediate positive in 3 patients, and strong positive in 2 patients. NPC with primary tumor volume $>100 \mathrm{ml}$ were weak positive in 1 patient and strong positive in 1 patients.

Statistical analysis the correlation between EGFR expression and primary tumor volume NPC measured using data ratio with normal distribution and Pearson's correlation test $(\mathrm{p}=0.047)$ with $(\mathrm{r})=0.461$. This shows intermediate EGFR expression found in primary tumor volume were related with coefisien. 


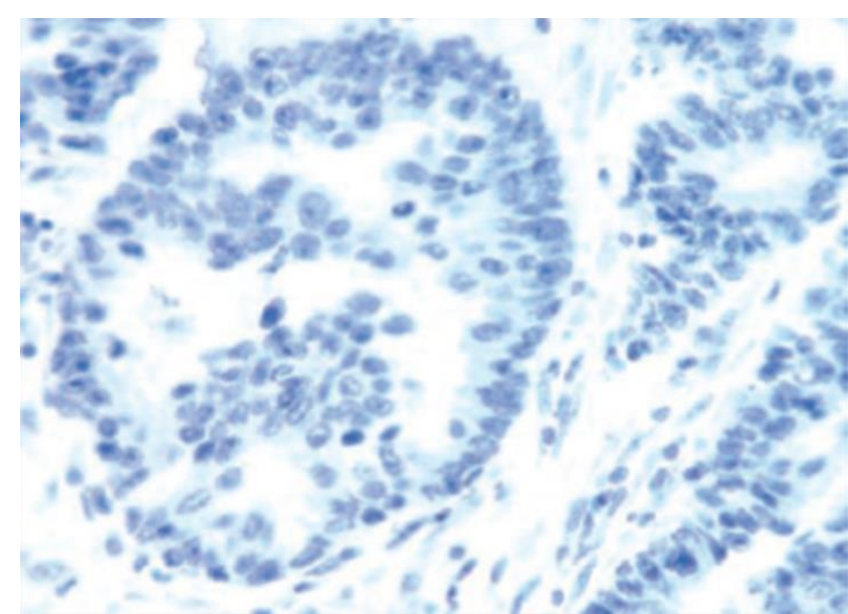

Picture 1. EGFR stain in NPC tissue shows no brownish red color appearance at membrane cell

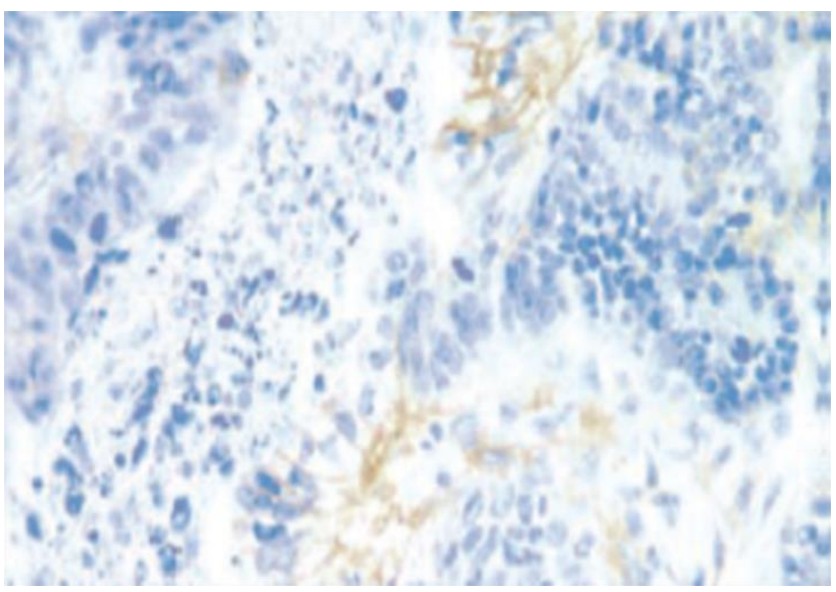

Picture 2. EGFR stain in NPC tissue shows weak intensity of brownish red color appearance at membrane cell

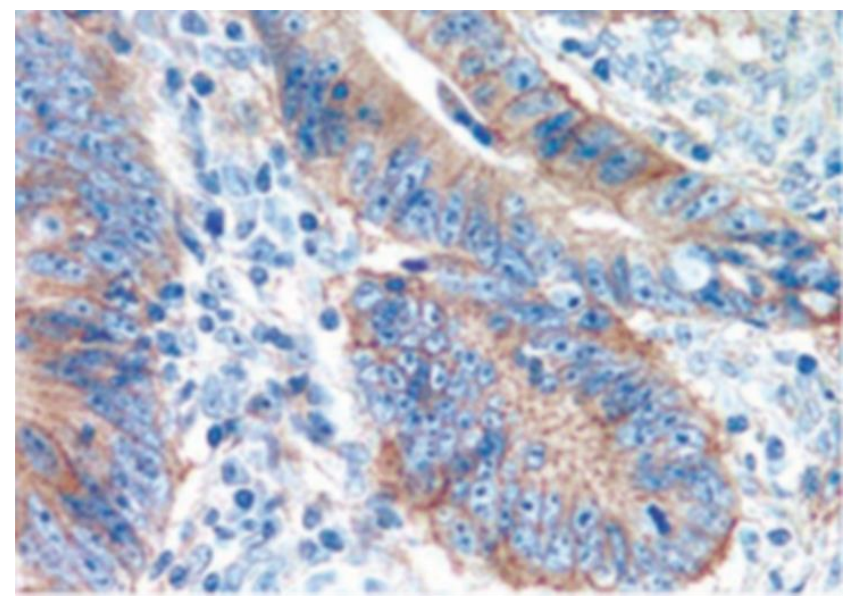

Picture 3. EGFR stain in NPC tissue shows intermediate intensity of brownish red color appearance at membrane cell

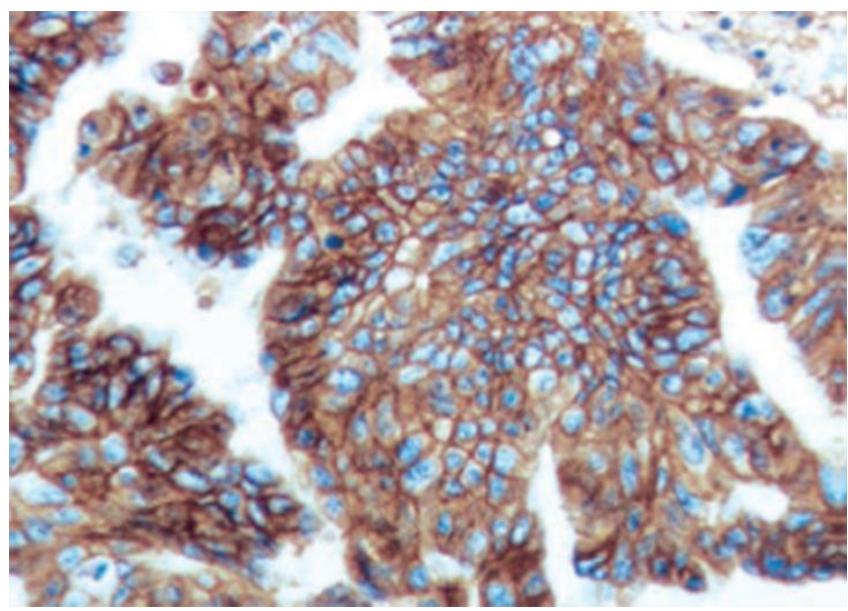

Picture 4. EGFR stain in NPC tissue shows strong intensity of brownish red color appearance at membrane cell

\section{DISCUSSION}

This study result showed the EGFR expression in NPC with primary tumor volume $1-50 \mathrm{ml}$ were weak positive in 5 patients and intermediate positive in 4 patients. NPC with primary tumor volume $51-100 \mathrm{ml}$ were negative in 2 patients, weak positive in 1 patient, intermediate positive in 3 patients, and strong positive in 2 patients. NPC with primary tumor volume $>100 \mathrm{ml}$ were weak positive in 1 patient and strong positive in 1 patient. Statistic analysis result showed there is a correlation between EGFR expression and primary tumor volume $(\mathrm{p}<0.05)$ with coefisien correlation $(r)=0.461$, there was an intermediate positive relation between EGFR expression and primary tumor volume.

The result is in accordance with the hypothesis, based on the theory that the NPC malignancy process indentify in EGFR signalling pathway. Braut et al., conducted study in 145 samples of biopsy tissue of head and neck squamous cell carcinoma using immunohistochemistry examination and found EGFR expression in control group were negative, hyperplastic group were weak positive, and carcinoma tissue were strong positive. The most significant changes was the supra basal layer [16]. Wang et al., found positive EGFR in 39 patients (70.9\%) from 55 NPC cases that underwent immunohistochemistry examination, meanwhile negative EGFR in $29.1 \%$ cases. Chua et al., found the positive EGFR expression using immunohistochemistry examination in biopsy results were $89 \%$, meandwhile negative EGFR were $11 \%$. The conclusion of the study there was no difference between EGFR expression with NPC staging, tumor size, lymph node enlargement, distant metastasis, age and gender. Sheen et al., found the positive EGFR $73.3 \%$ in all histology subtypes of NPC, consist of keratinizing squamous cell carcinoma in 6 cases, nonkeratinizing differentiated squamous cell carcinoma in 8 cases and nonkeratinizing undifferentiated in 27 cases [5].

EGFR gives intracellular transduction signalling pathway such as RAS/MAPK. The bond between growth factors and receptors are the initiation organization dan cell biochemistry process. The process are receptor activation, phosporilase cascade with indentification protein kinase and in nucleus level there is a transcription factors activation. EGFR system interaction and RAS/MAPK cascade is one of main cell pathways. Biological response to EGFR signal is pleiotrophic, including mitogenesis, inhibition apoptosis, induction cell motility, protein secretion and differentiation [17].

The effect of EGFR activation in tumor cell has many variations and also convergents that caused the uncontrollable cell growth, increased mobility, cell proliferation, invasion, metastasis, decreased of apoptosis and also stimulated the angiogenesis. In normal level of EGFR expressed by epithelial and mesenchymal cells. There were found increasing of EGFR expression in malignancy. Most of epithelial cancers expressed EGFR (over expression). EGFR over expression happens not only in NPC but also in others malignancies such as, colon carcinoma, glioma, ovarial carcinoma, kidney carcinoma, and lung carcinoma. The tumor cells with EGFR expression tent to be more aggressive and invasif [17].

The density of EGFR vary from nothing in the lymphoid cell until 250.000/keratin cell. Head and neck squamous cell carcinoma tend to twice 
bigger compare to normal cell to cond with monoclonal EGFR antibody, therefore the EGFR expression is the indicator of malignancy transformation and related with tumor differentiation. High level of EGFR expression showed in undifferentiated carcinoma and in case of poor prognosis carcinoma. Excess EGFR expression used as a predictor of tumor agresiveness, eventhough in head and neck squamous cell carcinoma the worse prognosis usually because of the uncontrolled distant metastasis. EGFR involved in carcinoma pathogenesis in head and neck and cause the disease progressivity $[4,16]$.

EGFR increased in many carcinomas, it is a transmembranne glycoprotein that produced by c-erb-B2 proto oncogen. This protein expressed only few in human body, but the proto oncogen activations caused many kind of carcinomas in human body. In physiology state, epithelias cell improperly proliferated due to response mitogenic ligan EGF that secreted autokrin or parakrin, or presented thru intercellular signalling that could activated the EGFR. The cell triggered to proliferated thru EGF during healing. Those signals started by one of 11 EGF members. The whole EGF ligands members included in proform as a precursore transmembranne proteins. The ligands converted become activated form that can diffused thru extracellular protein membrane breakdown [18].

The excessive EGFR expressions usually found in squamous cell carcinomas, either in tumor tissue or cell culture. EGFR expression barely found in normal squamous epithelial without cancer in control group, and increased when EGFR related with dysplasia and tumor. In normal squamous epithelial, EGFR laid in basal cell and indicated that the signals that conducted by EGFR were needed for proliferation. Many studies that showed EGFR in basal cell normal epithelial tissues, indicated there is a certain transformation mechanism that increase the EGFR expression dan cause the uncontrollable tumor proliferation. There is a hypothesis stated disregulation of EGFR happens in two steps, the first step is excessive EGFR expression in normal epithelial tissue that close to tumor. The second step is the changing from dysplasia becomes squamous cell carcinoma because of the excessive EGFR expression [4].

In normal condition, EGFR expression range from 40.000 until 100.000 receptors/cell. There is an increasing of EGFR expression about $80-90 \%$ in head and neck squamous cell carcinoma. The increasing found in the early phase of carcinogenesis and increase gradually when tumor size gets bigger, it can be marker to observe histology abnormality start from displaia until in situ carcinoma [19].

The mechanism of increasing EGFR in head and neck SCC in the early stage activated by conformational changes inducted by ligans (EGF, amphiregulin, and transforming factor alpha- TGF $\alpha$ ). Those changes caused dymerization of receptors that stimulate intrinsic tirosine kinase proteins activation, phosphoriyation and receptors activation. The receptors activation inducted a signal transduction, includes Ras/Raf/mitogenactivated protein kinas (MAPK), phosphoinositide 3-kinase (PI3K)-Akt, and transcription pathway activator. The MAPK that already phosphorylized will burn into nucleus, and making phosphorylation as a transcription factor that activated specific targeted gene expression, induce angiogenesis, proliferation, metastasis, invasion, and apoptosis inhibition [4].

Various studies show increasing EGFR expression predict poor prognosis and metastasis risk bigger in malignancy cases. EGFR expression reported as a prognosis factor in epithelial form of malignancy. The increasing EGFR expression usually uses to indentify big tumor size or related with distant metastasis [5].

The staging classification system using TNM that developed by YIML for NPC. T classification determined based on local anatomical location and cranial nerves that involved without quantitative criteria of tumor volume. Until now many studies have been conducted to link the tumor volume and controlled disease. NPC is the tumor that very infiltrative and tend to spread to soft tissue surround and skull base. Tumor volume can not be clinically measure easily without any modalities such as CT scan and MRI. The accurate assessment for tumor volume need tumor shape with several serials 3D imaging. There was many variations found of tumor volume from the same T classifications [20].

T-classification usually associated with local control and worse condition, therefore patients with different tumor volume eventhough with the same T-classification could give different prognostic [20].

Volume or tumor size have been known as two from many prognostic factors in malignancy therapy. The main purpose of staging in malignancy is to divide the patients into groups based on prognosis and to determine the right therapy. Big tumor size used as an assessment for staging by measuring the tumor size and its spreading. For the case with resectable tumor, tumor size becomes less important in local control. In the other hand for the unresectable case, tumor size becomes more important in local control because the increase ricks of clonogen and big size tumor tend to consist of hipoxic area that can leads to resistency in radiotherapy [20].

Chu et al., did retrospective study in 100 new cases of NPC from 20022006. The study used MRI for measure the primary tumor volume. This study showed primary tumor volume as a independent prognostic factor for distant metastasis, recurrency and quality of life after treatment [21].

Meanwhile according to Chua et al., primary tumor volume could not be use as a prognostic factor in early stage of NPC. Tumor volume $>15 \mathrm{ml}$ had the worse local control but from 5 years survival rate there is no significant difference [21]

The number of samples were 19 patients, sample collected from September untul December 2017. The sampe collection is done with randomized sampling method using inclusion and exclusion criterias. The study result there was intermediate positive correlation between EGFR expression and primary tumor volume $(\mathrm{p}<0.05)$.

Therapy response could be assessed based on primary tumor volume (staging) but in fact NPC patients with the same primary tumor volume could showed different response, therefore we still need another additional examination to predict the therapy response. The good understanding in correlation between EGFR expression and primaty tumor volume could be use to predict the therapy response using anti EGFR drugs.

\section{CONCLUSION}

Nasopharyngeal carcinoma (NPC) is a malignancy derived from nasopharyngeal epithelial cells. One of the molecular NPC markers is cluster of Epidermal Growth Factor Receptor (EGFR) who have responsible against the proliferation, differensiation, apoptosis, metastasis and drug resistance. This study aims to prove the association expression of EGFR with primary tumor volume in patients with NPC. The conclusion in this study explains that there was association between expression of EGFR with primary tumor volume in-patients with NPC.

\section{REFERENCE}

[1] Chong VF. Neoplasms of the nasopharynx. Head and Neck Cancer Imaging: Springer; 2008. p. 143-62.

[2] Taheri-Kadkhoda Z. Nasopharyngeal carcinoma: past, present and future directions: Inst of Clincial Sciences. Dept of Oncology; 2007.

[3] Wei W, Chua D. Nasopharyngal cancer. Dalam Bailey BJ, Healey GB, Johnson JT, Rosen CA dkk, penyunting. Head and neck surgeryotolaryngology Philadelphia Lippincott Williams \& Wilkins Edisi ke-4. 1875;97.

[4] Putti T, To K, Hsu H, Chan A, Lai G, Tse G, et al. Expression of epidermal growth factor receptor in head and neck cancers correlates with clinical progression: a multicentre immunohistochemical study in the Asia-Pacific region. Histopathology. 2002;41(2):144-51.

[5] Histawara S. Ekspresi Epidermal Growth Factor Receptor pada Karsinoma Nasofaring Subtipe Tidak Berkeratin di RSUP Dr. M. Djamil, Padang: Universitas Andalas; 2016.

[6] Scaltriti M, Baselga J. The epidermal growth factor receptor pathway: a model for targeted therapy. Clinical Cancer Research. 2006;12(18):5268-72.

[7] Chua D, Wong M, Wei W. Epidermal growth factor receptor expression correlates with poor outcome in patients with locally recurrent nasopharyngeal carcinoma treated by external beam reirradiation. International Journal of Radiation Oncology• Biology• Physics. 2008;72(1):S383-S4.

[8] Taheri-Kadkhoda Z, Magnusson B, Svensson M, Mercke C, BjörkEriksson T. Expression modes and clinical manifestations of latent membrane protein 1, Ki-67, cyclin-B1, and epidermal growth factor receptor in nonendemic nasopharyngeal carcinoma. Head \& neck. 2009;31(4):482-92.

[9] Cao XJ, Hao JF, Yang XH, Xie P, Liu LP, Yao CP, et al. Prognostic value of expression of EGFR and $\mathrm{nm} 23$ for locoregionally advanced nasopharyngeal carcinoma. Medical Oncology. 2012;29(1):263-71.

[10] Pan J, Tang T, Xu L, Lu JJ, Lin S, Qiu S, et al. Prognostic significance of expression of cyclooxygenase-2, vascular endothelial growth 
factor, and epidermal growth factor receptor in nasopharyngeal carcinoma. Head \& neck. 2013;35(9):1238-47.

[11] Tsang CM, Zhang G, Seto E, Takada K, Deng W, Yip YL, et al. Epstein-Barr virus infection in immortalized nasopharyngeal epithelial cells: Regulation of infection and phenotypic characterization. International journal of cancer. 2010;127(7):1570-83.

[12] Takada K, editor Role of EBER and BARF1 in nasopharyngeal carcinoma (NPC) tumorigenesis. Seminars in cancer biology; 2012: Elsevier.

[13] Iwakiri D. Epstein-Barr virus-encoded RNAs: Key molecules in viral pathogenesis. Cancers. 2014;6(3):1615-30.

[14] Ke K, Wang H, Fu S, Zhang Z, Duan L, Liu D, et al. Epstein-Barr virus-encoded RNAs as a survival predictor in nasopharyngeal carcinoma. Chinese medical journal. 2014;127(2):294-9.

[15] Fiorisa Es. Hubungan Antara Perubahan Kadar Imunoglobulin A Anti Early Antigen dengan Perubahan Volume Tumor Primer Pasca Kemoterapi Cisplatin-Paclitaxel pada Penderita Karsinoma Nasofaring: Universitas Airlangga; 2017.

[16] Braut T, Krstulja M, Kujundžić M, Manestar D, Hadžisejdić I, Jonjić $\mathrm{N}$, et al. Epidermal growth factor receptor protein expression and gene amplification in normal, hyperplastic, and cancerous glottic tissue: immunohistochemical and fluorescent in situ hybridization study on tissue microarrays. Croatian medical journal. 2009;50(4):370-9.

[17] Suharti C. Epidermal growth factor receptor (EGFR) sebagai sasaran terapi kanker kolorektal. 2009

[18] Arifianto A, Dewi YA, Aroeman N. Hubungan Ekspresi Epidermal Growth Factor Receptor Dengan Stadium Klinis Karsinoma Sel Skuamosa Kepala Leher.

[19] Zimmermann M, Zouhair A, Azria D, Ozsahin M. The epidermal growth factor receptor (EGFR) in head and neck cancer: its role and treatment implications. Radiation Oncology. 2006;1(1):11.

[20] Lu JJ, Cooper JS, Lee AW. Nasopharyngeal cancer: multidisciplinary management: Springer Science \& Business Media; 2010.

[21] Chua DT, Sham JS, Leung LH, Tai K, Au GK. Tumor volume is not an independent prognostic factor in early-stage nasopharyngeal carcinoma treated by radiotherapy alone. International Journal of Radiation Oncology* Biology* Physics. 2004;58(5):1437-44. 